Athens Journal of Business \& Economics -

Volume 7, Issue 4, October 2021 -Pages 365-378

\title{
Open Innovation: A New Source of Business Competitiveness
}

\author{
By Saïd Oubaziz* \& Dalila Matmar ${ }^{ \pm}$
}

The appearance and diffusion of new forms of innovation called open, lead us to question the relevance of this new paradigm, access to a reformulation of the traditional vision, dedicated to internal control of the $R \& D$ process, towards a broadening of practices, including external opportunities in terms of ideas, technologies and skills required. It is clear that the efforts of companies in the field of innovation must enable them to reach a significant level of control, which will allow them to obtain a strategic positioning in terms of competitiveness. However, the major transformations of the last 30 years, in the technological, social and economic fields, have had significant effects and a very strong impact on the level of competitiveness of companies. It is undeniable that innovation is not only the sign of the vitality of a company, according to (Schumpeter), but also, a base on which will be the sustainable economic development of a society. Several experiences in the world, show the development of innovative strategies in the field of innovation, in its different forms, which consist in implementing a policy of strengthening individual and collective initiatives, by implementing new models of support to innovation, as the model of open innovation. Indeed, this form of innovation management tends to strengthen inter-company relationships and to increase the exchange of information and cooperation between the company and its partners. The objective of this work is to highlight the challenges of open innovation, by structuring networked companies around open innovation (BCG and CMI report 2008), and the opportunities offered by the latter to companies. This new vision which, according to (Chesbrouch 2003), no longer consists in being satisfied with the internal resources of the company, but rather in relying on the capacity for innovation of multiple external stakeholders.

Keywords: open innovation, co-creation, crowdsourcing, business ecosystem, network ambidextria

\section{Introduction}

The search for greater competitiveness of companies and a better adaptation of organizational structures to changes in the economic, social and technological environment, which have become more complex, encourages them to set up new innovation strategies better suited to market needs and rapid changes in industry around the world.

\footnotetext{
"Research Assistant, Faculty of Economics, Business and Management Sciences, Mouloud Mammeri University of Tizi-Ouzou, Algeria.

${ }^{ \pm}$Professor, Faculty of Economics, Business and Management Sciences, Mouloud Mammeri University of Tizi-Ouzou, Algeria.
} 
Open innovation is a response to the company's need to open up its $R \& D$ process, combining ideas from the outside with technologies developed in-house.

Indeed, faced with market developments, the company is aware of the constraints posed by the various transformations resulting from an uncertain environment, and adopts a new logic of response for a better exploitation of the opportunities available to it.

For Chesbrough (2006) the company must mark a shift to another paradigm, which is the frame of reference for explaining the process of open innovation. This strategy is based on the need to open up externally through internal / external collaboration in order to generate more value. This is what he defines as a business model geared towards capturing and retaining value.

This strategy is integrated into $R \& D$ processes based on knowledge sharing and better exploitation of the potential offered by the internal and external ecosystem. The foundations of this model are based on the openness of society to the outside world in several areas, including innovation activity, which leads to a decompartmentalization of structures and to a collaboration between society and its environment, whether like a small business (Start-ups), or even very large companies such as global companies.

This innovation management responds to the need for companies to open up to their external environment. It is in fact an exploitation of the opportunities provided by shared research and development, as well as the dissemination and management of intellectual property through free licenses (open data, open source, etc.).

In other words, open innovation is a concept that introduces a new "interactive vision of innovation" which pushes towards the development of cooperation between companies and thus promotes the emergence of networks (Cohendet 1996), from cognitive spaces dedicated to sharing, which stimulates the construction and dissemination of ideas.

The objective of this article is to broaden our understanding of the practices generated by the open innovation process, as a phenomenon increasingly taken into account in the economic field, from a review of the literature in the field and strategies adopted to maintain a sustainable level of innovation. This contribution aims to identify this new source of competitiveness, with a more global vision of the new model, thus allowing a better appreciation of this new paradigm.

In the first part, we will return to the foundations of the open innovation model and the main features of the paradigm shift. We will continue in the second part by studying the process of open innovation and its ecosystem, as a way of adapting to change and its impact on the organizational structure of companies. The third section will demonstrate the benefits of open innovation at the strategic level as a competitive lever, for addressing multiple structural and opportunity management issues. 


\section{The Development of Open Innovation, a Paradigm Shift}

Chesbrough (2003) in his book "Open innovation: The new imperative to create and benefit from technology", lays the foundations of the new paradigm, which advocates the opening of the company to its ecosystem. Entitled open innovation, the author provides an analysis based on an observation of different companies in the United States, and proposes the idea of opening up research and development structures to their environments, which can be a source of benefits for the company. Indeed, this vision has a definite advantage in that it is faced with an environment marked by uncertainty and rapid change.

This model of innovation revolves around the opportunities offered by open innovation as a complement to the traditional model (closed innovation) deemed unsuitable for new realities, and that is the valuation of internal and external technologies

The assumption made by the author, is that companies can no longer rely exclusively on their own resources, but rather move towards the opening of structures and collaboration with the outside through the partnership. For Chesbrough (2003, p. 43) "Open Innovation means that valuable ideas can come from inside or outside the company, and can go to market from inside or outside the company as well. This approach places external ideas and external paths to market on the same level of importance as that reserved for internal ideas and paths to market during the Closed Innovation era".

He puts forward the hypothesis that new ideas can be of origin external to the enterprise and also internal to it. In the development of these ideas, the author argues his main lines of analysis, which is based on the hypothesis that innovation can be valued by the company on the market, and also in the other direction, by the capture and follow-up of ideas external to the organization.

For Dahlander and Gann (2010), the open innovation model obeys a transactional logic of property rights, whether with financial compensation or not (Table 1).

Table 1. Structure of Different Form of Openness

\begin{tabular}{|l|c|c|}
\hline & Inbound innovation & Outbound innovation \\
\hline Pecuniary & Acquiring & Selling \\
\hline Non-pecuniary & Sourcing & Revealing \\
\hline
\end{tabular}

Source: Dahlander and Gann 2010.

\section{Definition of the Concept of Open Innovation}

The definition of open innovation has several meanings that help delimit the scope of understanding of this new notion. Christensen et al. (2005) and Berkhout (2006) argue that open innovation is part of a perspective of economic evolution and industrial dynamics, thus laying the foundations of the knowledge economy on four key factors of innovation, a production which is capital, the labor, knowledge and finally creativity. 
Chesbrough (2006, p. 2) defines open innovation as "Open innovation is the use of purposive inflows and outflows of knowledge to accelerate internal innovation, and expand the markets for external use of innovation". Figure 1 shows the possible combinations, relating to the circulation of information (knowledge) sources of innovation, exploitable and above all profitable for the company. This consideration implies that the investment effort in internal $R \& D$ is no longer profitable for the company (loss of value), and that it is more strategic to go towards external knowledge (university, experts, engineers, etc.).

Figure 1. The Open Innovation Paradigm

\section{Open innovation}

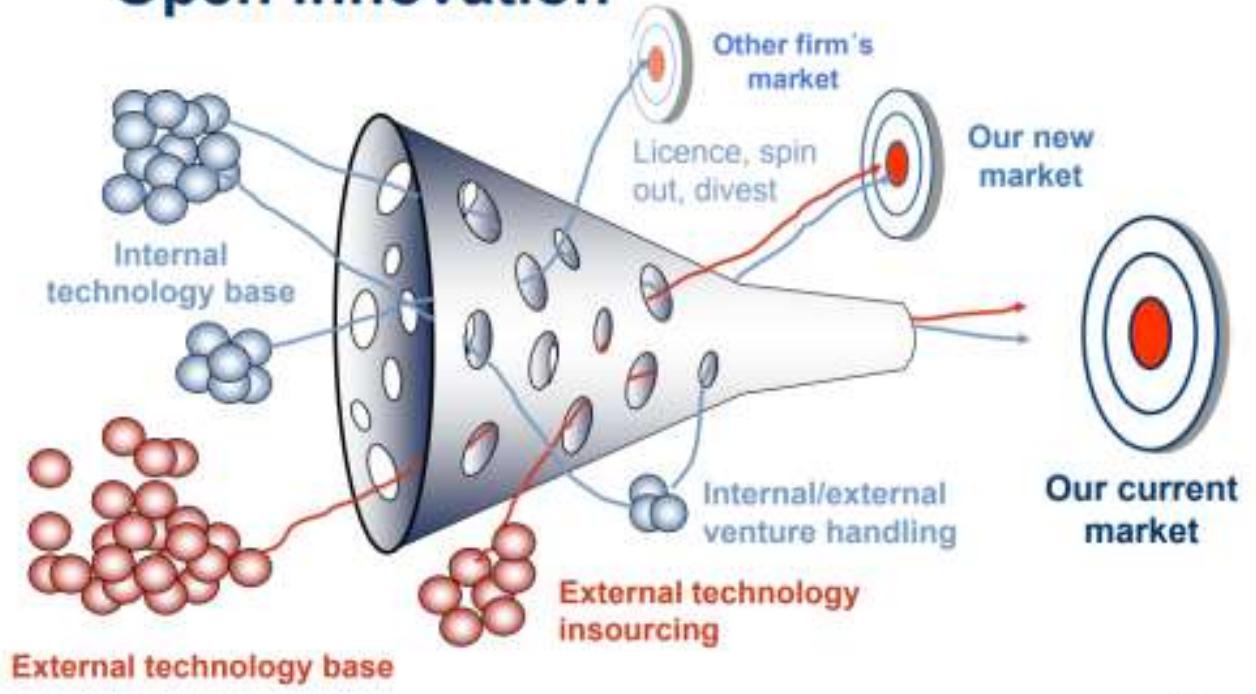

Source: Chesbrough 2004.

To do this, five principles must be brought together for the application of the new model:

- The active use of knowledge (incoming and outgoing flows) to accelerate the innovation process, and thus accept the fact that relevant ideas can also come from external sources.

- The rapid development of internal innovations, either by exploiting them or, failing that, by selling unexploited intellectual property.

- R\&D who can be done internally or externally, because in both cases there is profit generation.

- Accept ideas without looking for the origin of the fact that they are essential to success.

- The purchase of intellectual property is sometimes necessary to maintain a high level of competitiveness.

The concept of openness at Duval and Speidel (2014) means the ability of companies to rely on the collective, and especially on the collective intelligence of the actors of its ecosystem in its process of innovation. The process of opening 
allows the building of links between the firm and its ecosystem, by creating formal/ informal relations in the short and/or long term, with multiple and varied actors.

In their writings, Duval and Speidel (2014, p. 5) explain that "Open innovation covers the challenge and the ability of companies and organizations to involve all the collective intelligence of the players in its ecosystem - and beyond - in its innovation process". This ecosystem includes external stakeholders such as customers, suppliers, research laboratories, universities, SMEs, start-ups and major groups in its sector. However, it can also call on experts from industrial sectors other than those in its core business "individuals and companies beyond their natural ecosystem".

\section{Modalities for Setting up Open Innovation}

In 2007, Chesbrough and Appleyard in their article "open innovation and strategy", develop an analysis of the innovation strategy, and impose the idea that an investment in internal $R \& D$, is no longer justified, to from the observation that the increase in technology development costs, the reduction of product life and the reinforcement of intellectual property rights is increasingly reinforced. The model of open innovation and its notions of "ouside-in" and "ouside-out" is the way to optimize the company's revenue and even maximize value.

\section{The Three Open Innovation Processes}

The open innovation model involves three knowledge creation processes, in which the company markets internal and/or external ideas along two axes, from the outside to the inside and vice versa (see Table 2) (Pénin et al. 2013, pp. 15-16).

- Outgoing innovation axis (Inside-Out): this is the promotion of intellectual property from a commercial point of view, that is to say the dissemination of internal knowledge to customers (partners, competitors, etc.) in a traditional way. This logic is based on patents, technologies, publications, spin-offs, etc.Another technique of this process consists in revealing to the other market players of knowledge and technologies by an extension approach that generalizes its own technology and thus becomes a standard entity, and therefore the only entity capable of mastering innovation (radical). This technique helps to make innovation more efficient by opening up new markets and enabling the creation of new strategies, such as alternative brands, while promoting the emergence of co-development practices. This makes the limits of the company less narrow and allows multiplying the speakers, bearers of new ideas. 
Table 2. The Modalities of Open Innovation

\begin{tabular}{|l|c|c|}
\hline & Open innovation 1.0 & Open innovation 2.0 \\
\hline Outside-in & Licensing-in Spin-in & Crowdsourcing \\
\hline $\begin{array}{l}\text { Partership (mix of } \\
\text { outside-in and } \\
\text { inside-out) }\end{array}$ & $\begin{array}{c}\text { Co-design } \\
\text { Co-development } \\
\text { Research Consortium } \\
\text { joint-venture } \\
\text { Clusters }\end{array}$ & $\begin{array}{c}\text { Innovation with communities } \\
\text { / open source }\end{array}$ \\
\hline Inside-out & $\begin{array}{c}\text { Licensing-out Spin- } \\
\text { out }\end{array}$ & $\begin{array}{c}\text { Online marketplaces/ } \\
\text { "e-Bay des idées" (ex.: } \\
\text { Yet2.com) }\end{array}$ \\
\hline
\end{tabular}

Source: Pénin 2013 (free translation).

- The axis of incoming innovation (Outside-In): it is a strategy of openness, which allows a company, by a reverse process, to enrich its knowledge base through the network, by capturing ideas and solutions, the aim of which improve is the internal innovation process. It is a question of proceeding in a classical way, to the acquisition of knowledge or ideas, through the purchase of patents, licenses, technology transfer from the outside to the inside, to create joint ventures. This practice contributes to developing new forms of inter-company SME-TPE and large enterprise collaboration, and also between companies and their customers (users).

- The Coupled process: combines the first two axes in a real collaborative logic of pooling and co-creation in a network. It brings together several forms of platforms such as: the co-design, co-development, joint projects, alliances, participation in consortia, research cooperation ... the aim of this approach is to link tacit knowledge and explicit. This is a process that made the success of Open Source like the example of Linux.

\section{Crowdsourcing, a Web 2.0 Practice}

Burger-Helmchen and Pénin (2001) define crowdsourcing by two elements that characterize it: "an open call and a crowd, both of which are intrinsically linked. First of all, and contrary to usual outsourcing practices, in the case of crowdsourcing, the company does not rely on a single partner or a limited number of service providers, but it makes an open call. The open dimension is fundamental here. It means that access is non-discriminatory".

For Howe (2008), crowdsourcing "is the act of taking a task traditionally performed by a designated agent (such as an employee or a contractor) and outsourcing it by making an open call to an undefined but large group of people. Crowdsourcing allows the power of the crowd to accomplish tasks that were once the province of just a specialized few. Or to put it another way, crowdsourcing is to take the principles which have worked for open source software projects and apply them right across the entire spectrum of the business world".

With both definitions, we understand that the importance of two elements is essential to the functioning of the process; it is the notion of openness and open 
participation to all. In the sense of participation or more precisely the "solving problem" and "producing things" (Lakhani and Boudreau 2009, p. 63), and of content on the dedicated platforms, it is the second notion evoked that of the "ICT" information and communication technologies, thanks to the evolution of web 1.0 to web 2.0.

In practice, crowdsourcing refers to the outsourcing of internal tasks to a group of volunteer users on a collaborative platform. It is a technique that connects a community of dedicated experts with skills at the forefront of the innovation process.

The search for new ideas, pushes companies to collaborate with a relatively large mass on its external ecosystem, this collaboration lies in the establishment of creativity competitions (creative networks). This strategy has several advantages such as the mass of available resources and the speed of execution of the network by exploiting the intrinsic capabilities of web 2.0 (sharing software, open source platforms, use of ERP via cloud computing, data security, open information system, etc.).

According to Pénin (2013), five major reasons push organizations to resort to crowdsourcing, which are the following:

- The number and diversity of the crowd (on the internet) make it potentially very powerful to perform certain tasks. Using the crowd provides access to a pool of skills, ideas, resources, much larger than what the company has in-house.

- The use of crowds also allows a company to generate diversity, ideas and new projects. Crowdsourcing allows the organization to get out of the "incremental trap".

- Crowdsourcing rarely uses the remuneration of participants in very small proportions. It makes it possible to reduce the cost of carrying out certain tasks.

- In reality, the need for participation is much more a need to take on a challenge than to express a monetary need to get.

- It also increases competition in the performance of certain activities; putting internal teams in competition with a global pool of other researchers, stimulates them and improves their productivity.

- Lastly, crowdsourcing allows the organization to outsource the risks associated with an activity where the uncertainty factor is very high, while benefiting from the spin-offs resulting from the success of a project.

\section{Open Innovation, an Integrated Business Ecosystem}

The paradigm shift, evoked by Chesbrough (2003), moving from the closed innovation model to the open innovation model, introduces new challenges for production systems and their activities of innovation. Henceforth, in an increasingly complex environment, it is necessary for companies to change their business ecosystems through adjustments that can lead to the formalization of new organizational forms. 
Competitiveness Clusters, a Necessary Evolution of the Model towards Innovation 2.0

The creation of competitive clusters in France refers to the Blanc report (2004) presented to the government in the May 2004, whose purpose was to set up a new industrial policy. The designation of this strategy refers to the development of clusters across the Atlantic developed by Porter (1998) whose definition is "A cluster is a geographically proximate group of interconnected companies and associated institutions in a particular field, linked by commonalities and complementarities. The geographic scope of a cluster can range from a single city or state to a country or even a network of neighboring countries".

Mr. Porter's work focused on the study of business combinations in the same sector and on specific geographical areas, to explain the effectiveness of interactions between actors and the virtues of such a configuration mode. The example of Silicon Valley is a demonstration of the effectiveness of the "cluster" model, which will become a reference in terms of national economic policy.

In France, on the other hand, the development of the competitiveness clusters was based on an "addition of an industrial cluster and a scientific base where the synergy of a pole of excellence and a fabric of industries".

The objective of this strategy is therefore to benefit from the advantages that competitiveness clusters provide, based on a coopetitive logic, by cooperating with each other, and benefiting from the wealth of synergies and accumulated critical capacities (Blanc 2004).

The impact of the open innovation model on this type of concentrated organization and the changes brought about by modes of business-to-business cooperation marks a very important transition in the modes of cooperation between firms. From the classical network understood as a mode of organization and coordinating heterogeneous actors (Pesqueux 2004), towards a hybrid network, without necessarily a geographical reconciliation, which allows globally better support for the innovation ecosystem. It is the dimension developed by Chesbrough and Appleyard (2007) that concerns the renewal of the economic model, because to succeed in exploiting the gains made possible by open innovation, the introduction of new rules of the game is essential.

\section{The Business Ecosystem and Business Model, a Dynamic of Internal/External Rapprochement}

The concept of business ecosystem (ESA) is defined, as "It is no longer a single business, but heterogeneous coalitions of businesses competing. Alliances, partnerships, cooperation agreements help to create networks that no longer correspond to the concept of industry or the spinneret" (Torres-Blay 2000). This concept directs the company towards the creation of relations with external partners and stresses the need to bring out networks, which can correspond to an open innovation process, which takes into account several forms of inter-firm cooperation (collaborative platforms, co-innovation, co-creation, etc.). 
The idea is that the progress of open innovation in the economic field and the transformations induced by technological progress leads the company to open its business process outward; to a better capture, the value in the sense of Chesbrough (2006), and at the same time accompanies the exploitation of the ecosystem within the firm. It corresponds to an open innovation process in a situation of openness of the process, but also and more broadly to that of the opening of the business model (Pénin 2013).

This logic of rapprochement, revolves around the mobilization of skills, knowledge and capacity to master information technology and telecommunications (internet), in order to maximize the benefits of the open innovation model and there to develop more appropriate innovative structures.

\section{The Business Model of Open Innovation, a Lever of Competitiveness for Companies}

The problem of innovation is traditionally focused on the company's ability to develop innovations through its internal structure. Nevertheless, the new paradigm developed by Chesbrough (2003, 2006), leads us to reflect on the opportunities offered by open innovation and the answer what can it bring provide to solve problems such as the dilemma developed by Christensen (1997) as well as the case of the management of ambidexterity.

\section{The Dilemma of the Innovator versus Open Innovation}

Christensen (1997) describes in his work a phenomenon, that is the innovator's dilemma and where large companies find themselves trapped in their business models (profitability of incremental innovation) and miss out on the opportunities for disruptive innovations, thus losing the opportunity to secure their perenities. For Christensen (1997) "A good manager, from the traditional standards is the one who precisely cannot invest in path breaking products, services or technology [...] "Well managed" firms are doomed to miss disruptive innovation".

The logic that can explain this tension between incremental innovation and disruptive innovation (rupture) revolves around the notion of a business model, under which it "describes the logic of the way in which an organization creates, delivers, and captures value" (Osterwalder and Pigneur 2010, p. 14). For the author, the choice of a business model is based on nine questions, which are as follows (Osterwalder and Pigneur 2010, pp. 16-17):

- Customer Segments: the main customer segments to be addressed.

- Value Propositions: the value proposition to these customer segments.

- Channels: The most important channels to bring the product or service.

- Customer Relationships: Types of relationship to build with customers.

- Revenue Streams: the type of pricing product or service.

- Key Resources: the resources you need to create value.

- Key Activities: the main activities to create value. 
- Key Partnerships: outsourcing certain activities to partners.

- Cost Structure: the main components of your cost structure.

We propose three key logics to answer our problematic, which is that of the dilemma of the innovator. The first concerns the choice of the client, in relation to the technical aspect of breakthrough innovation, and with the technological changes adopted. Teece (2010) observes that the true desire of the consumers is one solution adapted to the needs that they manage to express, as for example, the passage of the laser printer to the printer with jet of ink; it is the logic Value Proposition.

The second logic is that of profit for the company (Revenue Streams), the best-known example is that of the company Kodak, which did not anticipate the evolution of the market and its passage to the technology of the digital photography.

The third logic revolves around the structure of the company through its resources, processes and values, thus integrating the cost structure, key resources, and finally, the control of the key activities as a source of added value, representing a first condition for success for the business model.

Christensen (1997) explains this paradox by the adopted business model, which prevents it from having strategies other than those of maximizing existing incomes. Indeed, disruptive innovations are only rarely introduced by the dominant firms in the market, but rather, by new entrants or newly created companies,

In the example of Christensen, the Kodak company that focuses on its film camera market (core business), and lacks the transition to digital photography.

USB keys, smartphones ... all these examples, show how dominant companies can miss a breakthrough innovation.

Open innovation as a new model oriented on the external ecosystem, can answer and provide a solution to this type of dilemma. To avoid falling into the trap of incremental innovation, Christensen offers several solutions, the most viable of which are to implement collaborative practices, create spin-offs, acquire external companies, etc., this strategy can be an adequate response to the paradox of the innovator

\section{Open Innovation, a Response to the Need for Ambidexterity}

The notion of ambidexterity is a notion that expresses a tension between the exploitation of existing resources and the exploration of new possibilities. March (1991) argues that organizations must mitigate this tension by organizational change between exploitation and exploration activities.

Levinthal and March (1993) express the idea that in order to maintain a longterm competitive advantage, the company must control its activities, accumulate experiences and, at the same time, develop them by way of experimentation.

The problem of innovation for firms is therefore in the search for dual structural form, which allows combinations capable of approaching ambidexterity. This answer lies in the concept of network ambidexterity (Ney et al. 2008), which can be defined as inter-firm cooperation within an innovation-generating network; because firms taken individually, cannot have sufficient research capacity and develop new ideas alone. 
This articulation of operational innovation and exploration is similar to the work of Chanal and Mothe (2005), who propose solutions to resolve this tension; she lies in the search for an optimal combination of exploration innovation and operating innovation.

This combination is precisely the dynamic capacity for innovation, which in summary introduces a logic of improvement of the competitive position of the company through innovation, and introduces hybrid, structures whose objective is to articulate its ability to organize relational competence internally and externally.

The network in open the innovation sense, provides the answer to this problem, it allows at a time to reconcile the activity of exploitation, by the focus on the core business, with the activity of exploration by the exploitation of external ideas and technologies.

\section{Conclusion}

The importance of innovation as a factor of sustainability and competition for organizations is well established. However, the change observed in recent years and the changing business environment lead us to question the maintenance of a sufficient level of competitiveness for companies knowing that the environment is increasingly complex.

Open innovation, as a new model articulated around the valorization of internal potentialities (exploitation of technologies), and also the necessary capture of external opportunities, offers the company these new possibilities to maintain its competitive position on the market.

Open innovation marks is the passage of a closing logic, concentrating internally the means to carry out R\&D and concretizing the projects of innovations, in a logic of protection of the intellectual property, with a logic of openness, allowing the exploitation and capture of ideas and technologies outside traditional structures, it is the new paradigm of open innovation developed by Chersbrough (2003).

The development of Web 2.0 tools making communication costs very low via IP telephony and social networks, the development of technologies adapted to the principle of sourcing such as crowdsourcing, co-creation and co-innovation, in a logic of creation /retention of value. Open innovation thus poses as a complement to closed innovation, thus increasing the capacity for innovation through two principles that are outside-in/inbound, and inside-out / outbound, with a mixed mode that brings together two preceding principles.

The advantage of open innovation lies in its ability to fully exploit the existing potential in the company and outside the company, from a business model integrating the ecosystem of innovation around a model business able to eliminate the constraints underlying the dilemma of the innovator and the difficulty of maintaining ambidextrous structure.

In conclusion, the open innovation model is a source of competitiveness as it has multiple benefits, focused on building the capacity of businesses, to maintain a 
level of sustainable efficiency and permanent flexibility, which is conducive to maintaining competitive advantage in markets hyper-complex.

\section{References}

Berkhout AJ, Hartmann Dap, Van Der Duin P, Ortt R (2006) Innovating the innovation process. International Journal of Technology Management 34(3/4): 390-404.

Blanc C (2004) Pour un écosystème de la croissance: rapport au premier ministre. (For an ecosystem of growth: report to the prime minister). Retrieved from: https://www.lado cumentationfrancaise.fr/rapports-publics/044000181/index.shtml. [Accessed 09 June 2019.]

Burger-Helmchen T, Pénin J (2011) Crowdsourcing: définition, enjeux, typologie. (Crowdsoursing: definition, challenges, typology). Revue Management et Avenir 1(41): 2-227.

ChanalV, Mothe C (2005) Concilier innovations d'exploitation et d'exploration: le cas du secteur automobile. (Conciliate exploitation and exploration innovation: the case of the automotive sector). Revue Française de Gestion 1(154): 173-191.

Chesbrough HW (2003) Open innovation - The new imperative for creating and profiting from technology. Boston, Massachusetts: Harvard Business School Press.

Chesbrough HW (2004) Open innovation: renewing growth from industrial R\&D. In $10^{\text {th }}$ Annual Convergence, Minneapolis Sept 2, 2004.

Chesbrough HW (2006) Open business models. Boston, Massachusetts: Harvard Business School Press, 107-143.

Chesbrough HW, Appleyard M (2007) Open innovation and strategy. California Management Review 50(1): 57-76.

Christensen C (1997) The innovator's dilemma: when new technologies causes great firms to fail. Boston, Massachusetts: Harvard Business School.

Christensen JF, Olesen MH, Kjaer JS (2005) The industrial dynamics of open innovation-Evidence from the transformation of consumer electronics. Research Policy 34(10): 1533-1549.

Cohendet P (1996) Recherche industrielle et processus d'innovation: le rôle structurant des pratiques de recherche. (Industrial research and the innovation process: the structuring role of research practices). Sociologie du Travail 96(3): 365-376.

Dahlander L, Gann DM (2010) How open is innovation. Research Policy 39(6): 699-709.

Duval M, Speidel K (2014) Open innovation: développer une culture ouverte et collaborative pour mieux innover. (Open innovation: developing an open and collaborative culture to better innovate). Paris: Ed. Dunod.

Howe J (2008) Crowdsourcing: why the power of the crowd is driving the future of business. Retrieved from: https://public.summaries.com/files/8-page-summary/crowd sourcing.pdf. [Accessed 09 June 2019.]

Lakhani KR, Boudreau KJ (2009) How to manage outside innovation. MIT Sloan Management Review 50(4): 68-76.

Levinthal D, March J (1993) The myopia of learning. Strategic Management Journal 14(Special Issue: Organizations, Decision making and strategy): 95-112.

March J (1991) Exploration and exploitation in organizational learning. Organization Science 2(1): 71-87.

Ney CJ, Favre-Bonte V, Baret C (2008) Vers un modèle de gestion de l'ambidextrie: innovation d'exploitation interne et coopération d'exploration. (Towards an ambidexterity management model: internal operating innovation and exploration 
cooperation). L'innovation organisationnelle: état des lieux, état de l'art. ESC STETIENNE.

Osterwalder A, Pigneur Y (2010) Business model generation. Hoboken, New Jersey: John Wiley \& Sons, Inc.

Penin J, Burger-Helmchen T, Guittard C, Dintrich A, Schenk E (2013) L'innovation ouverte: définition, pratiques et perspectives. (Open innovation: definition, practices and perspectives). CCI Paris Ile-de- France: Prospective et Entreprise. Éclairages sur les entreprises dans un monde ouvert.

Pesqueux Y (2004) Un "modèle" de l'organisation réseau? (A "model" of the network organization?) In Les réseaux: dimension stratégiques et organisationnelles, 27-43. Paris: Economica.

Porter M (1998) Cluster and the new economics of competition. Harvard Business Review 76(6): 77-90.

Teece DJ (2010) Business models, business strategy and innovation. Long Range Planning 43(2-3): 172-194.

Torres-Blay O (2000) Economie d'entreprise, organisation et stratégie à l'aube de la nouvelle economie. (Business economics, organization and strategy at the dawn of the new economy). Paris: Editions Economica coll. Entreprise 1er Cycle. 
